\title{
Comparison of surfactant mass transfer with drop formation times from dynamic interfacial tension measurements in microchannels
}

\author{
Maria Kalli, Loïc Chagot, Panagiota Angeli* \\ ThAMeS Multiphase, Department of Chemical Engineering, University College London, Torrington Place, London, WC1E 7JE, UK
}

\section{H I G H L I G H T S}

- The developed methodology measures dynamic interfacial tension down to $3 \mathrm{~ms}$.

- Surfactant adsorption times can be significant if compared to drop formation times.

- Dynamic interfacial tension was observed even with small-molecule surfactants.

- The proposed criteria ensure equilibrium interfacial tension during drop formation.

\section{A R T I C L E I N F O}

\section{Article history:}

Received 6 May 2021

Revised 28 June 2021

Accepted 29 June 2021

Available online 16 July 2021

\section{Keywords:}

Droplet formation

Surfactants

Dynamic interfacial tension

Flow-focusing microchannel
GR A P H I C A L A B S T R A C T

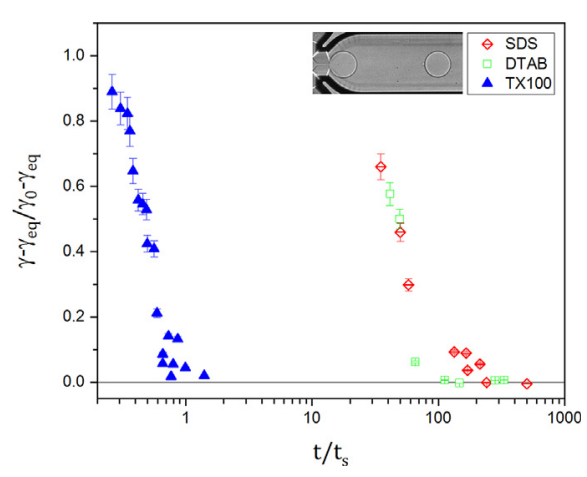

\begin{abstract}
A B S T R A C T
Dynamic interfacial tension was studied experimentally during drop formation in a flow-focusing microchannel. A low viscosity silicone oil ( $4.6 \mathrm{mPa}$ s) was the continuous phase and a mixture of $48 \%$ $\mathrm{w} / \mathrm{w}$ water and $52 \% \mathrm{w} / \mathrm{w}$ glycerol was the dispersed phase. An anionic (sodium dodecylsulfate, SDS), a cationic (dodecyltrimethylammonium bromide, DTAB) and a non-ionic (Triton ${ }^{\mathrm{TM}} \mathrm{X}-100, \mathrm{TX} 100$ ) surfactant were added in the dispersed phase, at concentrations below and above the critical micelle concentration (CMC). For SDS and DTAB the drop size against continuous phase flowrate curves initially decreased with surfactant concentration and then collapsed to a single curve at concentrations above CMC. For TX100 the curves only collapsed at surfactant concentrations 8.6 times the CMC. From the collapsed curves a correlation of drop size with capillary number was derived, which was used to calculate the dynamic interfacial tension at times as low as $3 \mathrm{~ms}$. The comparison of the surfactant mass transport and adsorption times to the interface against the drop formation times indicated that surfactant adsorption also contributes to the time required to reach equilibrium interfacial tension. Criteria were proposed for drop formation times to ensure that equilibrium interfacial tension has been reached and does not affect the drop formation.
\end{abstract}

() 2021 The Authors. Published by Elsevier Inc. This is an open access article under the CC BY license (http:// creativecommons.org/licenses/by/4.0/).
Abbreviations: DIT, dynamic interfacial tension; CMC, critical micelle concentration.

* Corresponding author.

E-mail address: p.angeli@ucl.ac.uk (P. Angeli).

\section{Introduction}

Microfluidic technologies have attracted significant research interest over the last decades, as they can be used to study physicochemical properties and to make complex products. They have been used to produce dispersions with a high degree of droplet 
monodispersity, which is appealing in processes involving emulsifications, microencapsulations, separations and reactions [1-4].

Often surfactants are added in dispersed two-phase systems to modify the interfacial properties, reduce drop size and improve stability through an interfacial layer that provides steric or electrostatic repulsions, in applications ranging from inkjet printing, to pharmaceutical processes and enhanced oil recovery [5-7]. During drop formation in a liquid in microchannels, a fresh interface is continuously formed. When surfactant molecules are present in either of the two phases, they will travel towards the new interface. Equilibrium interfacial tension values will only establish if the mass transport and adsorption of surfactants to the interface is fast compared to the drop formation time or the rate at which the new interface forms. In addition, convective flows around the forming droplets can result in uneven surfactant interfacial concentrations; these will induce interfacial tension gradients (Marangoni effects [8]) and introduce an additional complexity to the system. It is thus important to characterise the mass transfer and kinetics of surfactants in relation to fluid flowrates and droplet formation times and to determine the changes in interfacial tension over time or the dynamic interfacial tension (DIT).

Surface tension instruments can typically measure dynamic surface tension in the range of $0.1 \mathrm{~ms}$ - hours [9]. However, interfacial tension instruments rely on sphericity and thus require very small drops or a small density difference between the two fluids. As a result, the hydrodynamic effects inside the two phases can affect surfactant transport and limit the lower range of time scales that can be measured [9]. In addition, the sample preparation time can be long compared to surfactant diffusion and adsorption times. Javadi et al. [10] presented a summary of the experimental techniques available for obtaining different dynamic interfacial parameters at short interface ages and fast interfacial perturbations. Commercially available tensiometers for measuring dynamic surface and interfacial tension are based on different principles such as capillary pressure and drop volume $[9,11,12]$. In the former technique, a drop is formed from a nozzle and when the drop radius reaches that of the capillary, a maximum pressure is reached, which is used to calculate the interfacial tension from the Young-Laplace equation; the smallest time scale possible is $10 \mathrm{~ms}$ [13]. The latter tensiometer is based on a force balance on a forming drop just before it detaches from a capillary, i.e. when the drop weight overcomes the interfacial tension force; times down to $1 \mathrm{~s}$ can be reached [9]. The maximum bubble pressure tensiometer uses the same principle as the capillary pressure method in the submillisecond range $(0.1 \mathrm{~ms})$ but can only measure surface tension [14]. In addition, it was shown that convection becomes important below $0.1 \mathrm{~s}$, making it more difficult to obtain precise measurements at shorter time scales [15]. Interfacial tension instruments using drop profile analysis (pendant drop tensiometry, which is the most common method used for time scales $>1 \mathrm{~s}[9,12])$ and force tensiometry (Du Noüy ring or Wilhelmy plate) may not be representative of the flow conditions encountered when a drop forms in flow. Another disadvantage of force tensiometry is the disturbance caused to the interface when the ring or the plate contacts and stretches it to form a lamella. For surfactants with slow adsorption kinetics that require long measurements, the minor oscillations caused during lamella growth can cause surfactant molecules to redistribute and thus affect the measurement [16].

In more recent studies, microfluidics have been proposed as a means to obtain DIT at short time scales from 1 to $100 \mathrm{~ms}[6,17$ 19]. A common approach to determine DIT using microchannels is linked to drop formation and size. A force balance is considered in the dripping regime of drop formation [20], just before the drop detachment, between the viscous shear and the interfacial tension forces, and a correlation between the capillary number $\mathrm{Ca},=, \mu u_{\mathrm{c}} / \gamma$ (where $\mu, \mathrm{u}_{\mathrm{c}}$ and $\gamma$ are viscosity, continuous phase velocity and interfacial tension respectively) and the drop size at different flowrates is obtained. From this correlation, the interfacial tension can be estimated from the drop size at different conditions, at the corresponding drop formation time, giving the variation of interfacial tension with time. To obtain the correlation between Ca and drop size, it is important that the interfacial tension remains constant during the experiments. Systems without surfactants can be used, but it is not always possible to have drops forming at the relevant range of flowrates and capillary numbers as interfacial tensions are high. Surfactants are added to extend the ranges of flowrates where drops form, but in this case surfactant concentrations well above the CMC values need to be used to obtain constant interfacial tension $[18,21,22]$.

DIT has been investigated mainly in T-junction microchannels $[18,23]$ and co-flow microfluidic devices $[24,25]$. Flow focusing microfluidic devices are commonly used to produce droplets and exist in two configurations: hydrodynamic flow-focusing, where two liquid streams of the continuous phase surround the dispersed phase stream and break it to drops at the inlet $[22,26]$ and geometrical focusing where the breakup of the dispersed phase happens at an orifice of size smaller than the main microchannel width $[27,28]$. The latter configuration has previously been used to obtain DIT $[21,29]$ when surfactants are dissolved in the continuous phase, while the former configuration, is yet to be investigated. In 2006, Xu et al. studied the effects of flow, contact angle and wetting properties on the dynamics of plug and drop formation [20]. The axial droplet diameter, $\mathrm{d}$, was linked to the crossflow and was correlated as $d \sim \mathrm{d}_{\mathrm{i}} / \mathrm{Ca}$, where $\mathrm{d}_{\mathrm{i}}$ is the hydraulic diameter at the intersection of the channel. Wang et al. [18] used a Nhexane and Tween-20 mixture to develop a droplet diameter correlation for determining DIT from the capillary number down to $20 \mathrm{~ms}$. The results showed that by increasing the Tween-20 concentration in the continuous phase, surfactant adsorption is improved and the interfacial tension at the drop rupturing moment can be reduced to the equilibrium value. Xu et al. [21] added sodium dodecylsulfate (SDS) and hexadecyltrimethylammonium bromide (CTAB) surfactants in the continuous aqueous phase and found that DIT decreases with the N-hexane dispersed phase flowrate in the SDS case, suggesting that convection might play a role in the surfactant mass transport as opposed to the CTAB case. Brosseau et al. [17] used a sequence of microfluidic expansions to measure the droplet deformation and obtain kinetics of a perfluorinated surfactant at the sub-second time scale. Muijlwijk et al. [30] added SDS in the continuous phase and correlated the volume of hexadecane droplets to the capillary number at high expansion rates and within milliseconds.

There are also numerical studies on drop formation inside microchannels in the presence of surfactants. Riaud et al. [31] performed numerical simulations inside a T-junction microchannel using Span80-octane as the continuous phase and compared them against micro Particle Image Velocimetry ( $\mu$ PIV) experiments. The authors found that the interfacial distribution of surfactants on growing droplets is not uniform, but surfactants tend to concentrate at the droplet tip. Using Lattice Boltzmann simulations, Van der Graaf et al. [32] were able to predict well the shape and the final size of the drops. Their results showed that the droplet volume increases with increasing dispersed phase flowrate and decreasing capillary number. Jin et al. [33] studied the effect of soluble surfactants on the forming drop neck and used the Gibbs adsorption isotherm to relate interfacial tension to surfactant concentration at the interface, by accounting for maximum packing of surfactants.

It is important to know the interfacial tension variation with time to be able to operate microfluidic devices as generators of 
drops with controlled size. This paper presents a microfluidic approach that allows DIT to be measured in the millisecond scale, based on the drop formation times. The kinetics of three widely used surfactants, SDS, dodecyltrimethylammonium bromide (DTAB) and Triton ${ }^{\mathrm{TM}} \mathrm{X}-100$ (TX100), dissolved in the aqueous dispersed phase are characterised and their effects on drop formation are considered in a microfluidic device that combines both hydrodynamic and geometrical flow-focusing. From the results, correlations of drop size against the capillary number are developed, which are used to estimate the DIT during drop formation at an extended range of capillary numbers $(0.024 \leq \mathrm{Ca} \leq 0.263)$ and shorter time scales (down to $3 \mathrm{~ms}$ ) than what could be achieved before. By considering the various time scales relevant to the surfactant transport, we show that the surfactant adsorption times can be significant and should be considered during drop formation. Thus, we present criteria for minimum drop formation times needed to ensure that equilibrium interfacial tension has been reached and dynamic effects will not influence the drop size in the microfluidic channels.

\section{Materials, experimental methods and data processing}

\subsection{Materials and estimation of interfacial concentration}

The dispersed phase was a mixture of $52 \% \mathrm{w} / \mathrm{w}$ glycerol (SigmaAldrich, $\geq 99.5 \%$ ) and $48 \% \mathrm{w} / \mathrm{w}$ water (GS, density $=1132 \mathrm{~kg} / \mathrm{m}^{3}$, viscosity $=0.007 \mathrm{~Pa} \mathrm{~s}$ ) with and without surfactant, while the organic phase was a silicone oil (SO, density $=920 \mathrm{~kg} / \mathrm{m}^{3}$, viscosity $=0.0046 \mathrm{~Pa} \mathrm{~s}$, Clearco). The aqueous solution was chosen to be the dispersed phase, to avoid any surfactant adsorption to the channel walls. The $52 \% \mathrm{w} / \mathrm{w}$ water-glycerol solution was selected to match the refractive index of the oil phase $\left(n_{i}=1.39\right.$ at $\left.22{ }^{\circ} \mathrm{C}\right)$ and avoid any optical distortions from light reflection. All aqueous

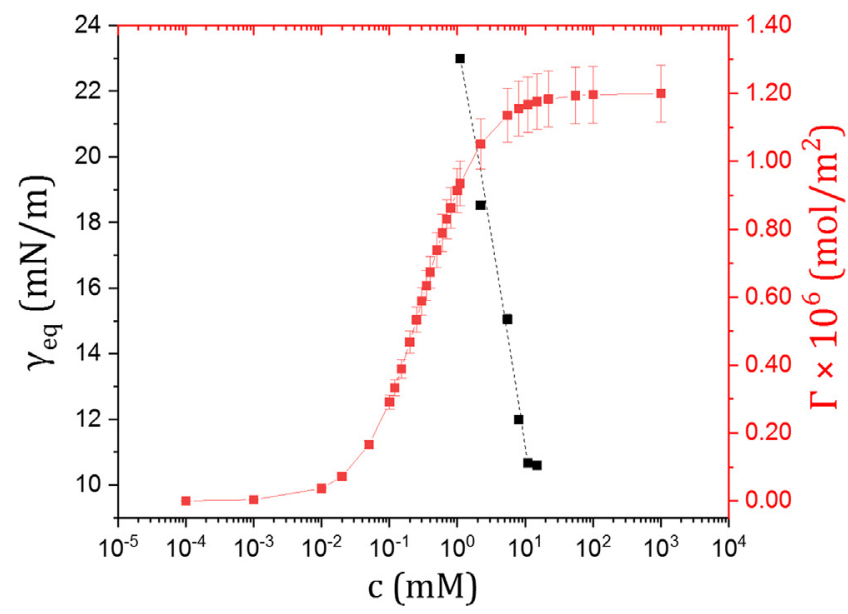

Fig. 1. Equilibrium interfacial tension and surface excess against concentration for SDS dissolved in $52 \% \mathrm{w} / \mathrm{w}$ glycerol solution. The dashed line is fitted to the experimental data. The continuous line represents the surface excess plotted on the secondary y-axis against surfactant concentration. solutions were prepared on the same day of each experiment in order to avoid undesired reactions between surfactants, water and glycerol [34-36].

Three types of surfactants were dissolved in the dispersed phase: the commonly used anionic surfactant sodium dodecylsulfate (SDS), $\left(V W R, M_{w}=288.38 \mathrm{~g} / \mathrm{mol}, \geq 99 \%\right.$ ), the cationic surfactant dodecyltrimethylammonium bromide (DTAB), (Santa Cruz Biotechnology, $\mathrm{M}_{\mathrm{w}}=308.34 \mathrm{~g} / \mathrm{mol}, 99.2 \%$ ) and the non-ionic surfactant Triton ${ }^{\mathrm{TM}}$ X-100 (TX100), (Acros organics, $\mathrm{M}_{\mathrm{w}}=646.85 \mathrm{~g} / \mathrm{m}$ ol, $>95 \%$ ). Equilibrium interfacial tension values, $\gamma_{\text {eq }}$, at different surfactant bulk concentrations, c, were measured experimentally using the Du Noüy ring attached to a Force K100 Tensiometer (Krüss $\mathrm{GmbH}$ ). Fig. 1 shows the interfacial tension isotherm for SDS at $22{ }^{\circ} \mathrm{C}$, from which the critical micelle concentration (CMC) value was found. The isotherms for DTAB and TX100 can be found in SI (see Figure S1(a)) while the CMC values for all surfactants are summarised in Table 1. As the CMC is expected to increase with the addition of glycerol in water, these values are higher than those reported in the literature for aqueous solutions [6,19]. These surfactants were chosen due to their differences in adsorption kinetics $[6,19]$.

The viscosities of the solutions were obtained with a Rheometer MCR 302 (Anton Paar GmbH) $\left(\mu_{d} / \mu_{c}=1.52\right.$, where $\mu_{d}$ and $\mu_{c}$ are the dynamic viscosities of the disperse and continuous phases, respectively). The results showed that the solutions remained Newtonian with the addition of surfactants. All measurements of density, viscosity and interfacial tension were taken at $22^{\circ} \mathrm{C}$ which is the temperature that the flow experiments were carried out. Table 1 summarises the fluid properties of the test solutions used in the experiments at CMC. Surfactant concentrations below and above CMC were used. Experiments were performed using c/CMC: $0.2,0.5,0.7,1.0,1.4,2.0,5.0$ for SDS; $0.5,1.0,2.5,5.0$ for DTAB and $0.1,0.2,0.6,1.0,1.4,2.1,2.9,4.3,5.7$ and 8.6 for TX100. Since TX100 is the only liquid surfactant in this study, a significant change in viscosity was observed at high TX100 concentrations so $\mathrm{c} / \mathrm{CMC}=8.6$ was the highest concentration used. Its solubility in the continuous oil phase could be neglected for the short time scale (milliseconds) relevant in this study, since its partition coefficient is large in favour of the aqueous phase [37]. The ionic surfactants (SDS, DTAB) are also considered to be insoluble in the organic phase.

The concentration of surfactants at the interface is usually estimated indirectly. The relationship between interfacial tension and concentration is given by the Langmuir-Szyszkowski isothermal equation of state $[12,38]$ :

$\gamma_{\mathrm{eq}}=\gamma_{0}-n R T \Gamma_{\max } \ln \left(\mathrm{K}_{\mathrm{L}} \mathrm{c}+1\right)$

where $\gamma_{0}$ represents the interfacial tension of the pure system without surfactant, $\mathrm{R}$ is the ideal gas constant, $\mathrm{T}$ is the temperature, $\Gamma_{\max }$ is the surfactant concentration at a saturated interface and $\mathrm{K}_{\mathrm{L}}$ is the ratio between the adsorption $\left(\mathrm{k}_{\mathrm{ads}}\right)$ and desorption rate $\left(\mathrm{k}_{\mathrm{des}}\right)$ constants. Since $1 \mathrm{~mol}$ of ionic surfactant will cause two ions to adsorb at the interface, $n=1$ is used for non-ionic surfactants and $n=2$ for ionic ones.

Once the values of equilibrium interfacial tension at different bulk surfactant concentrations are known, constants $\Gamma_{\max }$ and $\mathrm{K}_{\mathrm{L}}$

Table 1

Physical properties of the test fluids at surfactant concentrations equal to $\mathrm{CMC}\left(\mathrm{T}=22{ }^{\circ} \mathrm{C}\right)$.

\begin{tabular}{|c|c|c|c|c|c|}
\hline & Dispersed phase & Continuous phase & $\gamma_{\mathbf{e q}},(\mathbf{m N} / \mathbf{m})$ & $\Gamma_{\max }\left(\mathbf{m o l} / \mathbf{m}^{2}\right)$ & $\mathrm{K}_{\mathrm{L}}\left(\mathrm{m}^{3} / \mathrm{mol}\right)$ \\
\hline Pure / Surfactant-free & Aqueous glycerol solution (GS) (52\% w/w) & Silicone oil (SO) & 32.0 & - & - \\
\hline SDS & $\mathrm{GS}+\mathrm{SDS}$ at $\mathrm{CMC}=11 \mathrm{mM}\left(\mathrm{M}_{\mathrm{w}}=288.38 \mathrm{~g} / \mathrm{mol}\right)$ & & 10.7 & $1.20 \times 10^{-6}$ & 3.20 \\
\hline DTAB & $\mathrm{GS}+\mathrm{DTAB}$ at $\mathrm{CMC}=20 \mathrm{mM}\left(\mathrm{M}_{\mathrm{w}}=308.34 \mathrm{~g} / \mathrm{mol}\right)$ & & 10.0 & $1.70 \times 10^{-6}$ & 0.63 \\
\hline TX100 & $\mathrm{GS}+\mathrm{TX} 100$ at $\mathrm{CMC}=3.5 \mathrm{mM}\left(\mathrm{M}_{\mathrm{w}}=646.85 \mathrm{~g} / \mathrm{mol}\right)$ & & 2.9 & $1.42 \times 10^{-6}$ & 1585.00 \\
\hline
\end{tabular}




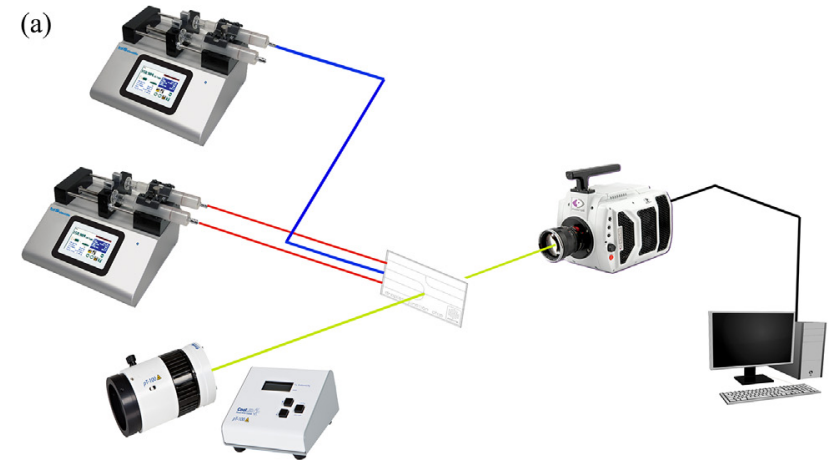

(b)

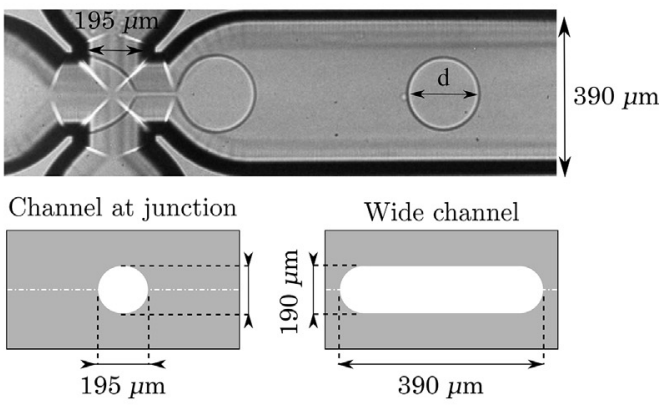

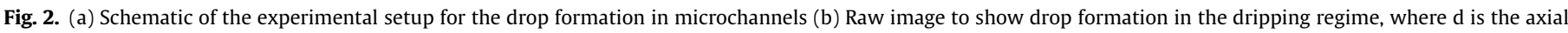
droplet diameter immediately after break-up and schematic of the flow-focusing inlet of the microchannel.

can be calculated by fitting Eq. (1) to the experimental data, as shown in Fig. 1 for SDS. The surface concentration, $\Gamma$, (surface excess) can be related to the corresponding bulk surfactant concentration using the Langmuir isotherm:

$\Gamma=\frac{\Gamma_{\max } \mathrm{K}_{\mathrm{L}} \mathrm{C}}{1+\mathrm{K}_{\mathrm{L}} \mathrm{C}}$

From Eq. (2), using the constants $\Gamma_{\max }$ and $\mathrm{K}_{\mathrm{L}}$ calculated, the surface excess at the liquid/liquid interface at different bulk concentrations was calculated for each surfactant, as illustrated in Fig. 1 (secondary y-axis); the values are given in Table 1 . As can be seen from Figure S1(b) in SI, TX100 reaches maximum surface coverage at lower bulk concentrations compared to the other surfactants, as mentioned in literature $[39,40]$.

\subsection{Drop formation experiments in microchannels}

The experimental setup for the drop formation studies is shown in Fig. 2(a). The experiments were performed in a glass microchannel (Dolomite Microfluidics, UK) with cross-junction inlet dimensions equal to $195 \mu \mathrm{m} \times 190 \mu \mathrm{m}$ (width $\times$ depth) and wide channels equal to $390 \mu \mathrm{m} \times 190 \mu \mathrm{m}$ (width $\times$ depth) (see Fig. 2 (b)). The images were taken with a 12-bit high-speed camera (Phantom v1212, $1280 \times 800$ pixels resolution) equipped with a Nivatar $12 \times$ zoom lens. A backlight system using LED ensured a homogenous illumination of the main channel. Two syringe pumps (KDS Scientific) were used for the liquids. The silicone oil was introduced first (continuous phase) via the top and bottom channels and then the aqueous phase (dispersed phase) was introduced via the central channel of the junction.

For all systems, the total continuous phase flowrates from top and bottom inlets $\left(Q_{c}\right)$ ranged from 0.02 to $0.4 \mathrm{~mL} / \mathrm{min}$, while the dispersed phase flowrates $\left(Q_{d}\right)$ varied from 0.01 to $0.1 \mathrm{~mL} /$ min. Depending on the system, these conditions were chosen as they resulted in regimes where drops formed, as shown in Fig. 2 (b). For each set of runs, the continuous phase flowrate was kept constant and the dispersed phase flowrate was increased in a stepwise manner. In order to capture the very fast dynamics of droplet formation, the images were acquired at a frequency of $10000 \mathrm{~Hz}$. Images were treated with codes developed in-house using MATLAB (R2017b) including detection of the liquid-liquid interface and calculation of droplet diameter, droplet velocity and formation time. Results were averaged for at least 15 drops (drop size polydispersity $<3 \%$ ). The drop formation time is taken as the number of frames from the pinch-off of a droplet until the detachment of the following droplet, divided by the frame rate of the camera $(10000 \mathrm{~Hz})$. The experimental errors can be considered negligible, being just $3 \mu \mathrm{m}$ per pixel for the spatial resolution $(2.5 \%$ of the smallest drop diameter) and $0.1 \mathrm{~ms}$ for the time resolution ( $13 \%$ of the smallest formation time). These errors will be shown using error bars on the graphs in the following sections.

\section{Results and discussion}

\subsection{Droplet characteristics}

The droplet size and formation time in the dripping regime for all three surfactants at different concentrations will be discussed in this section, which will be used to determine the DIT.

\subsubsection{Droplet size}

The average droplet diameters, $d_{a v}$, obtained upon addition of SDS, DTAB and TX100 in the aqueous phase are shown in Fig. 3 (a), (b) and (c) respectively, for constant $Q_{d}=0.01 \mathrm{~mL} / \mathrm{min}$. As shown in all three cases, drop size decreases with increasing $Q_{c}$, as a result of the pressure build-up on the side inlet channels and the high shearing effects along the drop interface which overcome the interfacial tension forces. As observed by Roumpea et al. [22] and Kovalchuk et al. [37], an increase in both of these factors with increasing $Q_{c}$ will accelerate the thinning rate of the neck and decrease the time required for the droplet to detach, resulting in smaller drop sizes. The results are in agreement with several literature findings [30,41,42].

An increase in surfactant concentration will decrease the interfacial tension and favour drop detachment which will decrease the drop size, in agreement with Wang et al. [18] and Roumpea et al. [22]. With a further increase in surfactant concentration and decrease in interfacial tension, the graphs collapse at a single line (Fig. 3(a) and (b)). This indicates that the equilibrium interfacial tension has been reached at the time scale of the drop formation. For both SDS and DTAB the curves collapse just after the $\mathrm{c} / \mathrm{CMC}=1.0$. On the other hand, with TX100, drop sizes continue to decrease, even with surfactant concentration at $\mathrm{c} / \mathrm{CMC}=8.6$, where $d_{a v}$ values become close but do not collapse completely (Fig. 3(c)).

\subsubsection{Drop formation time}

To be able to determine the DIT, the droplet formation time is needed. The drop formation times $(t)$ for the pure system without surfactant are shown in Fig. 4 against the continuous phase flowrate at different dispersed phase flowrates. As expected, formation time decreases with increasing continuous phase flowrate, due to the increased shear force from the continuous phase towards the drop. An increase in the dispersed phase flowrate decreases the formation time because it again increases the shear force between the two phases. The range of formation times observed is from 2.8 to $64.5 \mathrm{~ms}$. 

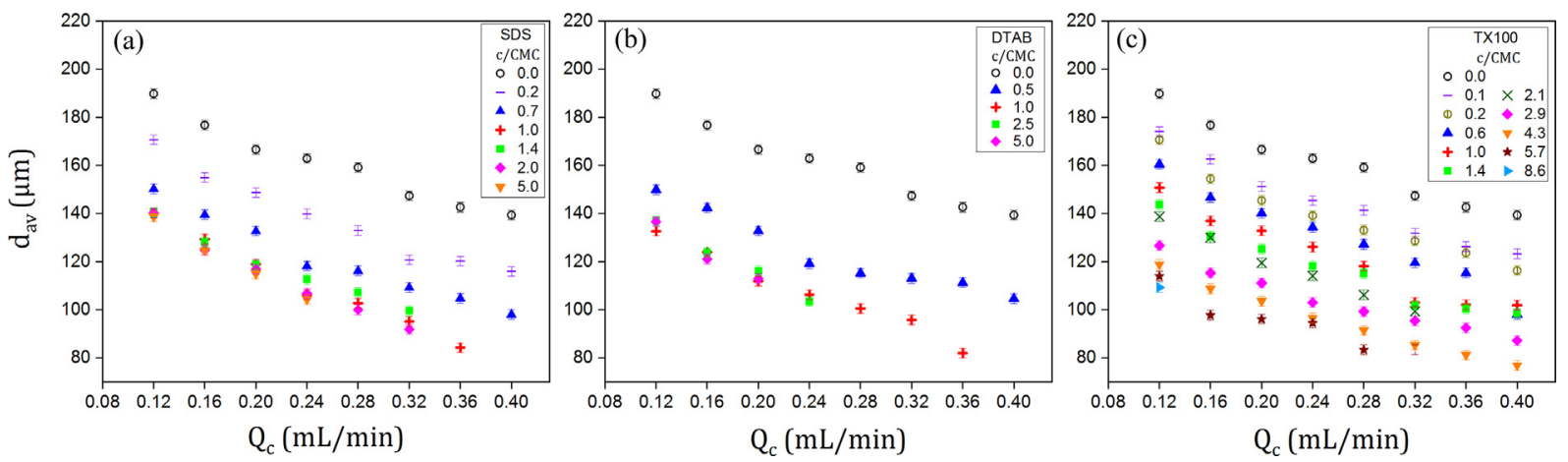

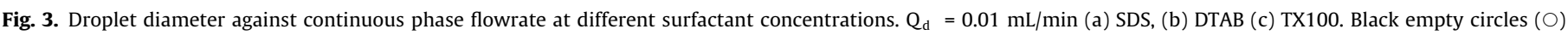
represent the pure system and red crosses $(+)$ indicate CMC solutions.

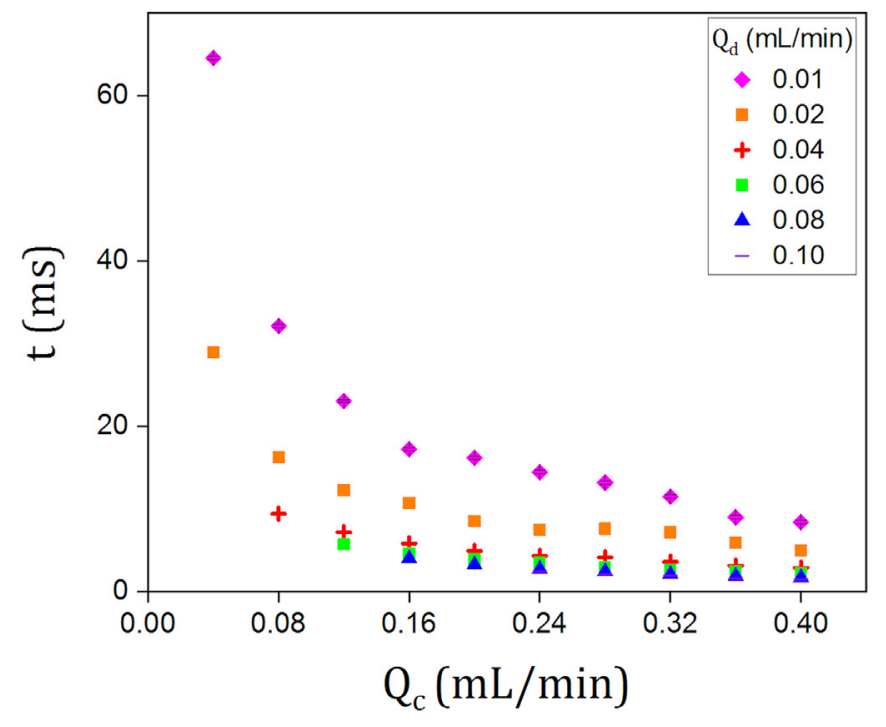

Fig. 4. Drop formation time against continuous phase flowrate at different dispersed phase flowrates for the pure system.

The effect of the continuous phase flowrate on the formation time upon addition of different SDS concentrations is shown in Fig. 5 for $Q_{d}=0.01 \mathrm{~mL} / \mathrm{min}$. Again, an increase in $Q_{c}$ decreases the drop formation time. An increase in SDS concentration also reduces the formation time until $\mathrm{c} / \mathrm{CMC}=1.0$, after which the curves collapse. The same trend is observed with the DTAB surfactant, whereas the curves did not collapse with the addition of TX100 surfactant, even at $\mathrm{c} / \mathrm{CMC}=8.6$. Similar results have also been reported for small-molecule surfactants (SDS) by Van der Graaf et al. [43] and for polymer surfactants (PVA) by Liu et al. [44].

\subsection{Dynamic interfacial tension}

As shown in Fig. 3(a) and (b), the drop sizes do not change above a certain concentration of the SDS and DTAB surfactants, denoting that an equilibrium interfacial tension has been reached during the drop formation process. In contrast, the graphs do not collapse at a single line when using TX100, suggesting that the time was not sufficient for the surfactant to saturate the interface. Nonetheless, $\mathrm{d}_{\mathrm{av}}$ values for $\mathrm{c} / \mathrm{CMC}=5.7$ and 8.6 are very close $(4 \%$ difference) and can be used for the DIT analysis. The surfactant-free data at $0.16 \mathrm{~mL} / \mathrm{min} \leq \mathrm{Q}_{\mathrm{c}} \leq 0.4 \mathrm{~mL} / \mathrm{min}$ and $0.02 \mathrm{~mL} / \mathrm{min} \leq \mathrm{Q}_{\mathrm{d}} \leq$ $0.1 \mathrm{~mL} / \mathrm{min}$, where the interfacial tension is constant, were also used to extend the range of interfacial tensions considered (2.9 $\mathrm{mN} / \mathrm{m} \leq \gamma \leq 32 \mathrm{mN} / \mathrm{m}$ ). The surfactant-laden data used were at

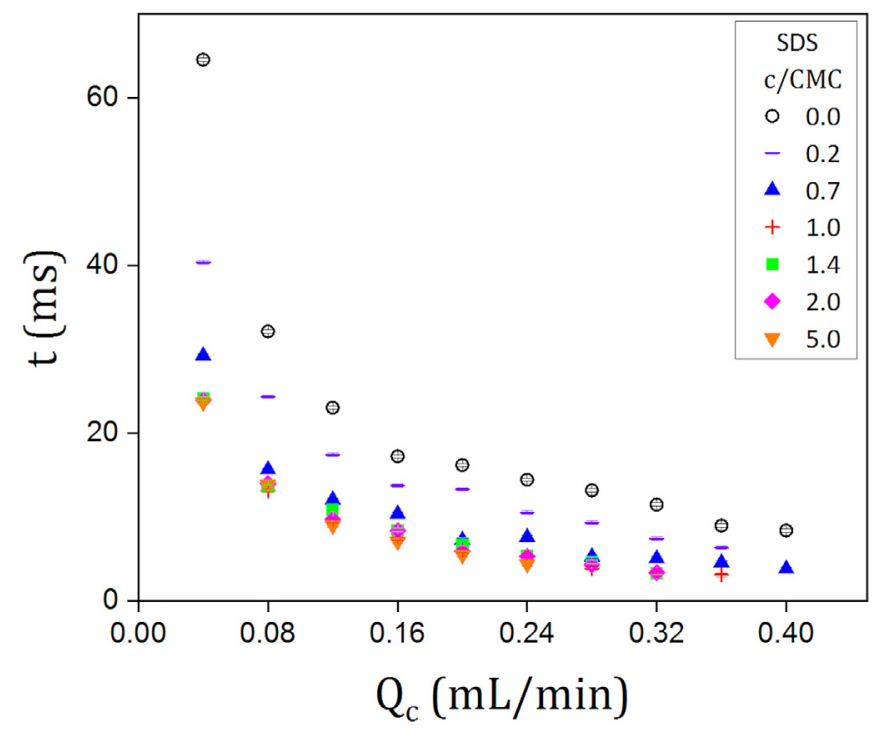

Fig. 5. Drop formation time against continuous phase flowrate at different SDS concentrations. $Q_{d}=0.01 \mathrm{~mL} / \mathrm{min}$, red crosses (+) indicate CMC solutions.

a constant $\mathrm{Q}_{\mathrm{d}}=0.01 \mathrm{~mL} / \mathrm{min}$ and $0.08 \mathrm{~mL} / \mathrm{min} \leq \mathrm{Q}_{\mathrm{c}} \leq 0.32 \mathrm{~mL} /$ $\mathrm{min}$. These flowrate ranges were chosen as the squeezing regime $[14,22]$ was observed at lower $Q_{c}$, and tip streaming-jetting [45] was seen at higher $Q_{c}$. Following the model from $\mathrm{Xu}$ et al. [46], the experimental data on drop size was fitted to the following equation, for $0.031 \leq \mathrm{Q}_{\mathrm{d}} / \mathrm{Q}_{\mathrm{c}} \leq 0.125$ and $0.024 \leq \mathrm{Ca} \leq 0.263$.

$\frac{\mathrm{d}_{\mathrm{av}}}{\mathrm{d}_{\mathrm{n}}}=0.642\left(\frac{\mathrm{Q}_{\mathrm{d}}}{\mathrm{Q}_{\mathrm{c}}}\right)^{0.188}\left(\frac{1}{\mathrm{Ca}}\right)^{0.161}$

where $d_{n}$ is the characteristic length of the flow-focusing device (channel width at junction $=195 \mu \mathrm{m}$ ). The continuous phase velocity needed in the capillary number was obtained from $u_{c}=Q_{c} / A_{\text {inlet }}$, where $A_{\text {inlet }}$ is the area corresponding to the cross-sectional area of the inlet junction as shown in Fig. 2(b).

Fig. 6 compares the experimental data with those calculated from the model, showing good agreement (standard deviation $\sigma=2 \%$ ). Using Eq. (3) the DIT at unsaturated interfaces for all surfactants can be calculated at different drop sizes at the corresponding formation times. DIT values against drop formation time at different surfactant concentrations are plotted in Fig. 7(a), (b) and (c) for SDS, DTAB and TX100, respectively. As expected, DIT decreases with increasing drop formation time in all three cases, as more time is available for the surfactant to transfer to the interface before the drop pinch-off. In the case of SDS, at $\mathrm{c} / \mathrm{CMC}=0.7 \mathrm{a}$ 


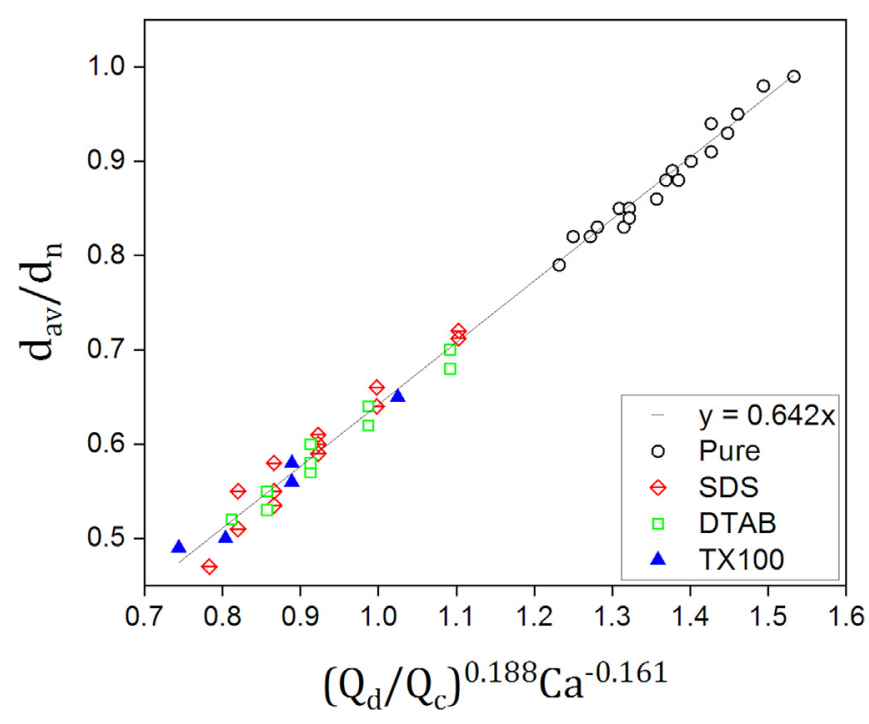

Fig. 6. Model from Equation (3) (continuous line) and experimental data used for surfactants free and surfactant laden solutions (symbols).

plateau is not reached, and DIT values are far from the equilibrium value of $12 \mathrm{mN} / \mathrm{m}$, as measured using ring tensiometry. At higher concentrations, from CMC and above, a plateau is reached which is very close to the equilibrium value of $10.7 \mathrm{mN} / \mathrm{m}$. The same behaviour was seen with DTAB, where the equilibrium value of $16 \mathrm{mN} / \mathrm{m}$ is approached at increasing drop formation time at around $\mathrm{c} / \mathrm{CMC}=0.5$. DIT values reached the equilibrium ones of $10 \mathrm{mN} / \mathrm{m}$ for $\mathrm{c} / \mathrm{CMC}=1.0$ and $\mathrm{c} / \mathrm{CMC}=2.5$ at all drop formation times studied.

On the other hand, with the TX100 surfactant, the equilibrium interfacial tension during drop formation is not reached for most studied concentrations (Fig. 7(c)). The DIT curve at $\mathrm{c} / \mathrm{CMC}=0.6$ is far from the equilibrium value of $3.7 \mathrm{mN} / \mathrm{m}$. The DIT values at $\mathrm{c} / \mathrm{CMC}=4.3$ and $\mathrm{c} / \mathrm{CMC}=5.7$, however, approach the final equilibrium value of $2.9 \mathrm{mN} / \mathrm{m}$. This is attributed to the differences in adsorption kinetics of the three surfactants during drop formation $[33,47]$. From dynamic surface tension measurements in the millisecond scale, it was found that surfactants with low CMC values equilibrate slower, because of the low surfactant molecule concentrations in the bulk $[14,39]$. The CMC values of the studied surfactants decrease as follows DTAB > SDS > TX100 (see Table 1), with TX100 having the lowest CMC value. Partearroyo et al. [48] who studied these surfactants in urea, reported that they reach equilibrium values at $\mathrm{c} / \mathrm{CMC}$ ratios that follow the sequence $\mathrm{DTAB}<\mathrm{SDS}<\mathrm{TX100}$, which is in agreement with the above find- ings. Surfactant kinetics will be further discussed in the next section.

The DIT values against drop formation time at a higher dispersed phase flowrate, $0.02 \mathrm{~mL} / \mathrm{min}$ are compared with the values at $0.01 \mathrm{~mL} / \mathrm{min}$ in Fig. 8, for all three surfactants at $\mathrm{c} / \mathrm{CMC}<1.0$. The DIT values are lower for the higher dispersed phase flowrate, even though the drop formation times are shorter. Short formation times would have been expected to decrease the concentration of surfactant adsorbed at the drop interface and increase the DIT values. A similar behaviour was reported by Wang et al. [18], who argued that high dispersed phase flowrates enhance convection and surfactant mass transfer to the interface, thus justifying the reduced interfacial tension values. As reported by Wang et al. [19], TX100 is convective mass transfer controlled at low concentrations. Xu et al. [21] described a similar phenomenon for the SDS system. Convection both inside and outside drops seems to be important and will be explored in future work using novel particle image velocimetry techniques [22].

\subsection{Drop formation times in relation to surfactant kinetics}

Surfactant adsorption to liquid-liquid interfaces from a bulk phase can be divided into three discrete steps: (1) Mass transfer (diffusion and/or convection) of surfactant molecules from the bulk to the depletion length (i.e. a layer with thickness of only a few molecular diameters or angstroms below the interface layer) [49]; (2) Kinetic adsorption of surfactant to the interface [12,50]; (3) Disaggregation of micelles and dissolution of some of the surfactant molecules that were previously bound to the micelles, caused by the imbalance between micelles and molecules in the bulk solution [51].

According to Eastoe and Dalton [52], there are two models describing surfactant transport from the bulk to the interface: (1) The diffusion or mass transfer limited model, assumes that the monomer transfer from the bulk into the depletion layer is the rate-controlling step and adsorption from the depletion layer to the interface is fast and can be neglected. (2) The mixed kinetic model assumes that adsorption of surfactant molecules between the interface and the depletion layer is the slow step and the monomer transport in the bulk phase is fast. Barriers for adsorption include limited 'vacant sites' available on the interface, increased surface pressure, steric constraints on the molecules close to the interface and wrong orientation of the monomers, especially for long chain surfactants, proteins and polymers [52]. From the above it is evident that the mechanism that controls the DIT during drop formation depends on surfactant type, concentration and flow conditions. Drop formation times should be longer than the mass transfer and adsorption times for surfactants to
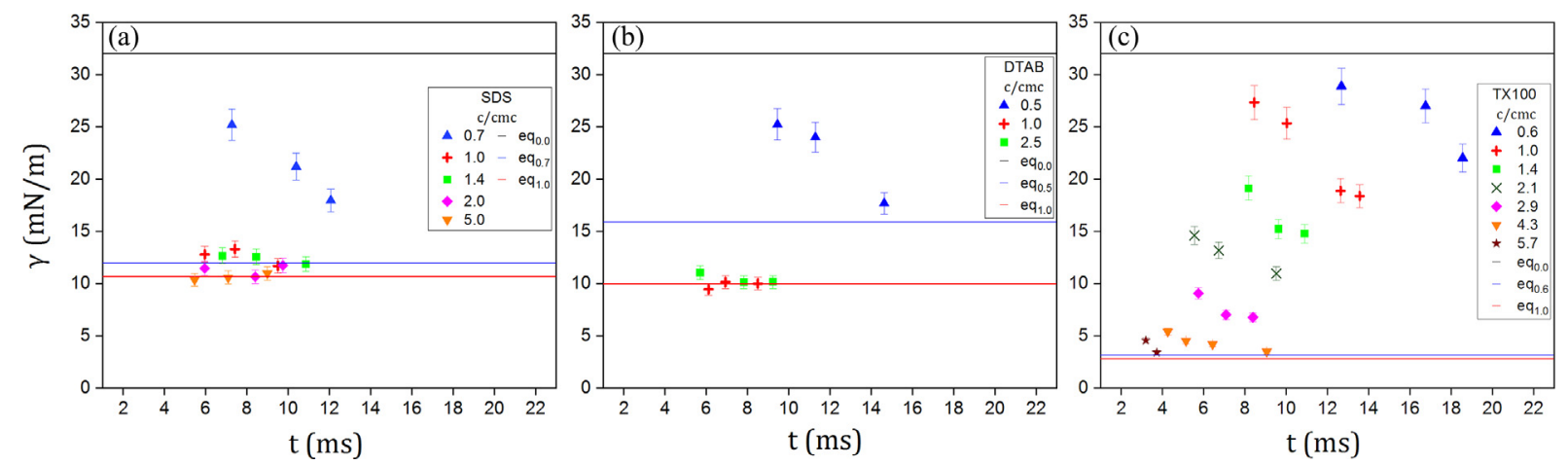

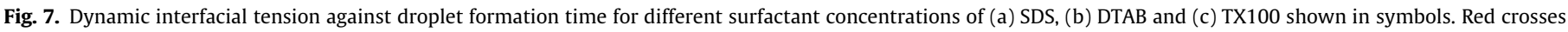
(+) indicate CMC. Solid lines represent equilibrium interfacial tension values measured using a Du Noüy ring attached to a Force K100 Tensiometer (Krüss GmbH). 


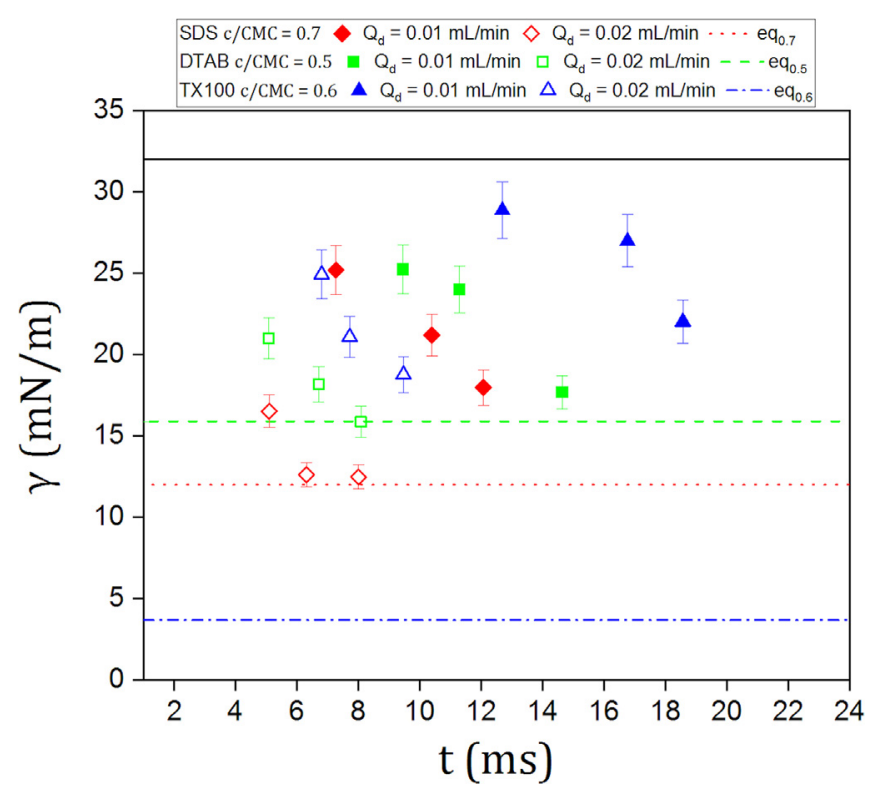

Fig. 8. Effect of dispersed phase flowrate on the dynamic interfacial tension for all three surfactants at concentrations below CMC $\left(0.12 \mathrm{~mL} / \mathrm{min} \leq \mathrm{Q}_{\mathrm{c}} \leq 0.2 \mathrm{~mL} / \mathrm{min}\right)$.

reach equilibrium concentration at the interface. In this section we discuss the relevant time scales to understand the DIT values obtained above.

In order to obtain a time scale for the mass transfer of the surfactant, an appropriate length scale needs to be defined. For laminar flow and a planar interface [19,53], mass transfer depends on diffusion in the depletion length [39]. The thickness of the depletion length, $h_{p}$, can be derived from the mass balance of the surfactant on the interface and on the volume in the bulk phase that it once occupied given by $\Gamma A_{s}=c V_{s}$, where $A_{s}$ and $V_{s}$ are the surface area and the volume of the depletion layer, respectively. Since $\mathrm{V}_{\mathrm{s}}=\mathrm{h}_{\mathrm{p}} \mathrm{A}_{\mathrm{s}}$, the depletion length is defined as $\mathrm{h}_{\mathrm{p}}=\Gamma / \mathrm{c}$. The characteristic time for the diffusion of the surfactant in the depletion length is [54]:

$\mathrm{t}_{\text {diff }}=\frac{\mathrm{h}_{\mathrm{p}}^{2}}{\mathrm{D}}$

where $\mathrm{D}$ is the diffusion coefficient of the monomers. For the mass transfer of surfactants during laminar flow inside drops, the size of the drops may also be a relevant length scale [23]. For large drop diameters however, $\left(d_{a v} / h_{p}>10\right)$, the interface can be assumed to be flat, and Eq. (4) can be used.

For concentrations above the CMC, an effective diffusion coefficient, $D_{\text {eff }}$ should be used instead to account for the effect of the dissolution of micelles on the mass transfer of the surfactant. The monomers released after micelle disaggregation increase the surfactant diffusivity (up to 2 orders of magnitude). According to Glawdel and Ren [55], $\mathrm{D}_{\text {eff }}$ can be found from:

$\mathrm{D}_{\mathrm{eff}}=\mathrm{D}(1+\beta)\left(1+\beta \sigma^{2}\right)$

where $\beta=(\mathrm{c} / \mathrm{CMC})-1, \sigma=\mathrm{N}_{\mathrm{A}}^{-1 / 3}, \mathrm{~N}_{\mathrm{A}}=$ aggregation number showing the number of monomers needed to form a micelle.

According to Jin et al. the characteristic time scale for the adsorption-desorption of the surfactant to the interface (assuming Langmuirian kinetics) is given by [56]

$\mathrm{t}_{\mathrm{ads}}=\frac{1}{\mathrm{~K}_{\mathrm{ads}} \mathrm{C}+\mathrm{K}_{\mathrm{des}}}$

Jin et al. suggested a critical size, $\mathrm{R}_{\mathrm{DK}}$, to compare the importance of the adsorption and diffusion phenomena, given by [56]
$\mathrm{R}_{\mathrm{DK}}=\frac{\mathrm{D}}{\Gamma_{\max } \mathrm{K}_{\mathrm{ads}}}$

If the $R_{D K}$ value is smaller than the drop radius $\left(d_{a v} / 2\right)$, then the surfactant transport is diffusion controlled. If $R_{\mathrm{DK}}$ is comparable to or larger than the drop radius, then adsorption becomes important. In the presence of convective flows or circulation patterns inside or around the drops [22,31] which can accelerate surfactant mass transport, different length scales for the surfactant mass transport in the bulk phase would need to be taken into account $[19,23,57,58]$.

The diffusion coefficients (D) of the studied surfactants at $\mathrm{c} \leq \mathrm{CMC}$ were estimated using the Wilke-Chang correlation [59] (Table 2) and showed good agreement when compared with literature values $[6,14,60]$. The effective diffusion coefficients $\left(D_{\text {eff }}\right)$ at c > CMC were calculated using Eq. (5). The diffusion coefficients of the surfactants are similar, while the calculated effective diffusion coefficients are higher compared to the monomer ones, due to micelle disaggregation. DTAB has the shortest depletion lengths at corresponding concentrations both below and above $\mathrm{CMC}$, while TX100 has the largest $h_{p}$ at corresponding $c / C M C$ values. As a result, the diffusion mass transfer times, $t_{\text {diff }}$, calculated from Eq. (4), at surfactant concentrations both below and above CMC follow the sequence of DTAB $<$ SDS $<$ TX100.

The desorption coefficients $\left(\mathrm{k}_{\mathrm{des}}\right)$ are given in Table 3 as found from literature at $\mathrm{c} / \mathrm{CMC}=1.0$ in water. Using the calculated $\mathrm{K}_{\mathrm{L}}$ values from Table 1 , the adsorption coefficients $\left(K_{\mathrm{ads}}\right)$ were obtained from $\mathrm{K}_{\mathrm{L}}=\mathrm{K}_{\mathrm{ads}} / \mathrm{k}_{\mathrm{des}}$ [56] and the adsorption times, $\mathrm{t}_{\mathrm{ads}}$, were calculated from Eq. (6). The calculated adsorption times using $\mathrm{k}_{\mathrm{des}} \mathrm{val-}$ ues at different concentrations were of the same order of magnitude as the ones reported in Table 3. For small drops and the low concentrations of all surfactants considered in this study, adsorption at the interface is negligible compared to the amount of surfactant available in the bulk, so no depletion of surfactant in the drop takes place.

As can be seen, for SDS and DTAB surfactants at $c<C M C$, $\mathrm{t}_{\mathrm{ads}}<\mathrm{t}_{\text {diff }}$, denoting a diffusion limited mass transfer mechanism with relevant time scale $t_{s}=t_{\text {diff }}$. At CMC, $t_{\text {ads }}=0.069 \mathrm{~ms}$ is smaller than $\mathrm{t}_{\text {diff }}=0.113 \mathrm{~ms}$ for SDS so $\mathrm{t}_{\mathrm{s}}=\mathrm{t}_{\text {diff }}$, and $\mathrm{t}_{\mathrm{ads}}=0.067 \mathrm{~ms}$ is similar to $t_{\text {diff }}=0.062 \mathrm{~ms}$ for DTAB so $t_{s}=t_{\text {diff }}$. Above the CMC, $t_{\text {ads }} \sim t_{\text {diff }}$ for SDS, while for DTAB $t_{\text {ads }}>t_{\text {diff }}$, so $t_{\text {ads }}$ is taken as the characteristic time scale, $t_{s}=t_{a d s}$. For the TX100 surfactant, $t_{\text {ads }} \sim \mathrm{t}_{\text {diff }}$ below CMC, $t_{\text {ads }}>t_{\text {diff }}$ at CMC and $t_{\text {ads }} \gg t_{\text {diff }}$ by 2 orders of magnitude above CMC, so $t_{s}=t_{a d s}$ at all TX100 concentrations. The significance of adsorption with the TX100 surfactant is also seen by comparing the critical sizes $R_{D K}$ with the drop size. The $R_{D K}$ value $(23.8 \mu \mathrm{m})$ at high TX100 concentrations is of the same order of magnitude as the drop radius $(40-70 \mu \mathrm{m})$, suggesting that adsorption is also important.

Table 2

Characteristic parameters for surfactant mass transfer.

\begin{tabular}{llll}
\hline & SDS & DTAB & TX100 \\
\hline $\mathrm{c} / \mathrm{CMC}$ & $0.2,0.5,0.7,1.0$, & $0.3,0.5,0.7$, & $0.6,1.0,1.4,2.1$, \\
& $1.4,2.0,5.0$ & 1.0, & $2.9,4.3,5.7$ \\
& & $2.0,2.5$ & \\
$\mathrm{D}\left(\mathrm{m}^{2} / \mathrm{s}\right)$ & $1 \times 10^{-10}$ & $9 \times 10^{-11}$ & $5 \times 10^{-11}$ \\
$\mathrm{~N}_{\mathrm{A}}[19,32]$ & 74.5 & 55 & 101 \\
$\mathrm{~h}_{\mathrm{p}}(\mu \mathrm{m})$ & $0.022-0.478$ & $0.033-0.334$ & $0.071-0.708$ \\
$\mathrm{t}_{\text {diff }}(\mathrm{ms})$ & $2.281,0.426,0.208$, & $1.117,0.229$, & $10.013,3.271$ \\
$\mathrm{c} \leq \mathrm{CMC}$ & 0.113 & $0.156,0.062$ & \\
$\mathrm{t}_{\text {diff }}(\mathrm{ms})$ & $0.044,0.014,0.001$ & $0.008,0.004$ & $1.100,0.316$, \\
$\mathrm{c}>\mathrm{CMC}$ & & & 0.129, \\
& & & $0.036,0.014$ \\
\hline
\end{tabular}


Table 3

Kinetic constants, adsorption times and critical size lengths at all concentrations.

\begin{tabular}{llll}
\hline & SDS & DTAB & TX100 \\
\hline $\mathrm{k}_{\text {des }}(1 / \mathrm{s})[61,62]$ & 400 & 1100 & 0.0065 \\
$\mathrm{~K}_{\text {ads }}\left(\mathrm{m}^{3} / \mathrm{mols}\right)$ & 1280.0 & 694.5 & 10.3 \\
$\mathrm{t}_{\text {ads }}(\mathrm{ms})$ & $0.014-0.134$ & $0.028-0.124$ & $4.8-48.5$ \\
$\mathrm{R}_{\text {DK }}(\mu \mathrm{m})$ & $0.034-0.072$ & $0.081-0.222$ & $3.5-23.8$ \\
\hline
\end{tabular}

For $\mathrm{c} \leq \mathrm{CMC}$, drop formation times are $5.9 \mathrm{~ms} \leq \mathrm{t} \leq 15 \mathrm{~ms}$ using SDS and DTAB. When compared to the calculated $t_{\text {diff }}$ values (the relevant time scale) of $0.113 \mathrm{~ms} \leq \mathrm{t}_{\text {diff }} \leq 2.281 \mathrm{~ms}$ for SDS and $0.062 \mathrm{~ms} \leq \mathrm{t}_{\text {diff }} \leq 1.117 \mathrm{~ms}$ for DTAB, it can be seen that drop formation times are comparable or longer than the diffusion times and thus DIT approaches equilibrium during the drop formation. For $\mathrm{c}>\mathrm{CMC}$, the drop formation times of $5.5 \mathrm{~ms} \leq \mathrm{t} \leq 10.9 \mathrm{~ms}$ are 2 orders of magnitude longer than the calculated $t_{\text {ads }}$ values of $0.014 \mathrm{~ms} \leq \mathrm{t}_{\mathrm{ads}} \leq 0.035 \mathrm{~ms}$ for SDS and $0.028 \mathrm{~ms} \leq \mathrm{t}_{\mathrm{ads}} \leq$ $0.066 \mathrm{~ms}$ for DTAB and equilibrium is very quickly reached (Fig. 7(a) and (b)). As mentioned above, the relevant time scale is $\mathrm{t}_{\mathrm{s}}=\mathrm{t}_{\text {diff }}$ at concentrations below CMC and $\mathrm{t}_{\mathrm{s}}=\mathrm{t}_{\mathrm{ads}}$ above CMC.

For the TX100 surfactant at $\mathrm{c} \leq \mathrm{CMC}$, the adsorption times of $27.7 \mathrm{~ms} \leq \mathrm{t}_{\mathrm{ads}} \leq 48.5 \mathrm{~ms}$ are larger than the drop formation times of $5.6 \mathrm{~ms} \leq \mathrm{t} \leq 16.8 \mathrm{~ms}$. This explains why equilibrium interfacial tension values are not reached with TX100 and a DIT is expected. Also, at TX100 concentrations above CMC, adsorption times $4.8 \mathrm{~ms} \leq \mathrm{t}_{\mathrm{ads}} \leq 19.4 \mathrm{~ms}$ are closer to but generally larger than the drop formation times of $3.2 \mathrm{~ms} \leq \mathrm{t} \leq 9.1 \mathrm{~ms}$ so a DIT is also expected as seen in Fig. $7(\mathrm{c})$. At $\mathrm{c} / \mathrm{CMC}=4.3$ and 5.7 , the $\mathrm{t}_{\mathrm{ads}}=4.8 \mathrm{~ms}-6.5 \mathrm{~ms}$ values are similar to drop formation times $\mathrm{t}=4.7 \mathrm{~ms}-5.2 \mathrm{~ms}$, which explains why equilibrium interfacial tension is approached at high concentrations.

Normalised dynamic interfacial tensions $\left(\frac{\gamma-\gamma_{\mathrm{eq}}}{\gamma_{0}-\gamma_{\mathrm{eq}}}\right)$ are plotted against the normalised drop formation time $\left(t / t_{s}\right)$ as shown in Fig. 9. Normalised times $>1$, denote that the surfactant transport to the interface is faster than interface generation, whereas a value of 0 for the normalised interfacial tension denotes that the equilibrium value has been reached. As can be seen, for the TX100 surfactant, equilibrium interfacial tension values in the microchannel can be reached at $t / t_{s}>1$, as opposed to DTAB and SDS surfactants that require $t / t_{s}>110$ and $t / t_{s}>240$ to reach equilibrium,

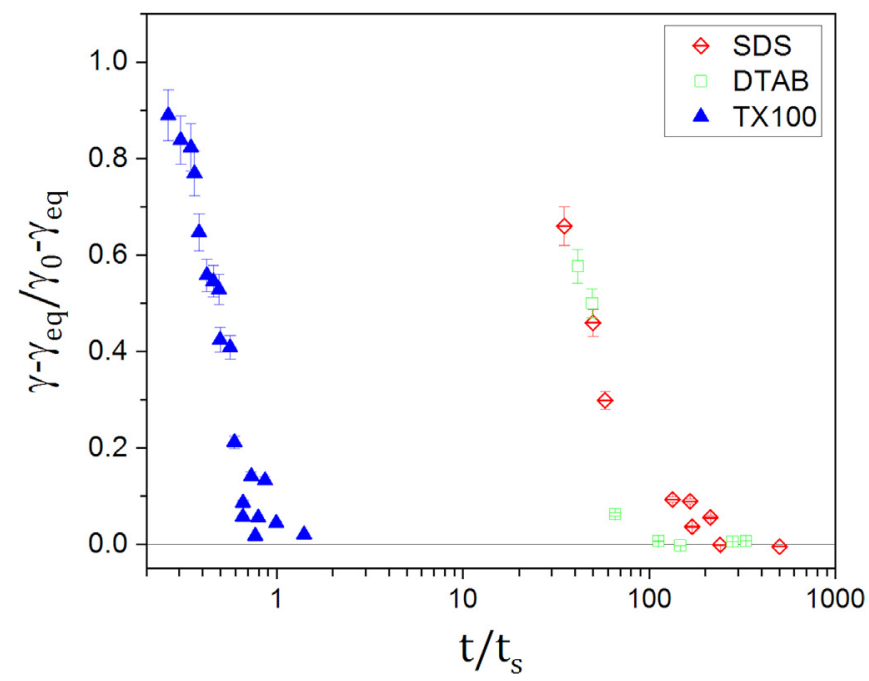

Fig. 9. Normalised interfacial tension against normalised drop formation time. The criteria of $t / t_{s}>1$ for TX100, $t / t_{s}>110$ for DTAB and $t / t_{s}>240$ for SDS are shown, where the normalised interfacial tension falls to 0 and equilibrium interfacial tension, $\gamma_{e q}$ is reached.
Table 4

Comparison of the results with similar systems found in literature.

\begin{tabular}{|c|c|c|c|}
\hline & $\begin{array}{l}\text { Wang et al. } \\
{[18,19]}\end{array}$ & Moiré et al. [6] & Current work \\
\hline $\begin{array}{l}\text { Surfactants } \\
\text { considered }\end{array}$ & $\begin{array}{l}\text { SDS, CTAB, TX100, } \\
\text { Tween } 20\end{array}$ & DTAB, TX100 & SDS, DTAB, TX100 \\
\hline $\begin{array}{l}\text { Surfactant } \\
\text { transport step } \\
\text { considered }\end{array}$ & Mass transfer & Mass transfer & $\begin{array}{l}\text { Mass transfer } \\
\text { and Adsorption }\end{array}$ \\
\hline $\begin{array}{l}\text { Minimum t for } \\
\text { DIT (ms) }\end{array}$ & 6 & 11 & 3 \\
\hline $\begin{array}{c}\text { Criteria } t / t_{s} \text { for } \\
\text { equilibrium }\end{array}$ & $\begin{array}{l}\text { Constant for all } \\
\text { surfactants }>3\end{array}$ & $\begin{array}{l}\text { Constant for all } \\
\text { surfactants } \\
>4-5\end{array}$ & $\begin{array}{l}\text { Variable depending } \\
\text { on surfactant type } \\
>240,>110,>1\end{array}$ \\
\hline
\end{tabular}

respectively. The findings are compared in Table 4 against similar systems from the literature $[6,18,19]$. Previous studies only considered the time required for the mass transfer of the surfactants, while the adsorption time was not taken into account. We show here that the adsorption times can be significant and should be considered when comparing the drop formation times with the time required for the surfactant to transfer to the interface. As discussed above, adsorption times are significant in the case of TX100 for all surfactant concentrations and for SDS and DTAB for c > CMC. In addition, by considering low concentrations (below $\mathrm{CMC}$ ) and high flowrates, we show that even with smallmolecule surfactants [63], such as SDS and DTAB, equilibrium interfacial tension may not be reached during the drop formation time. Wang et al. [19] reported that SDS is in equilibrium within the whole range of $80<\mathrm{t} / \mathrm{t}_{\mathrm{s}}<4000$ at concentrations above CMC, while we found that at concentrations below CMC there is a DIT for $35<\mathrm{t} / \mathrm{t}_{\mathrm{s}}<213$.

\section{Conclusions}

The changes in dynamic interfacial tension (DIT) over time were studied experimentally during drop formation inside a flowfocusing microchannel in the presence of different surfactants. The surfactants used, SDS, DTAB and Triton X-100 (TX100) were dissolved in a $52 \% \mathrm{w} / \mathrm{w}$ glycerol solution which was the dispersed phase, while a low viscosity silicone oil ( $4.6 \mathrm{mPa}$ ) was the continuous phase. The effects of surfactant concentrations and flowrates of the two phases on drop size and drop formation time were investigated, using high speed imaging. These results were used to determine the DIT at short time scales $(3 \mathrm{~ms})$ that cannot be reached with commercial instruments or found in previous literature $[6,18,19,21,24]$.

It was found that drop size decreased as the continuous oil phase flowrate increased and as the surfactant concentration increased. The curves of the drop size against the continuous phase flowrate collapsed for SDS and DTAB surfactants at concentration values above the critical micelle concentration (CMC), denoting saturated interfaces within the droplet formation time and thus equilibrium interfacial tension. On the other hand, with the TX100 surfactant the curves were similar only at very high concentrations of about 8.6 times the CMC value. The collapsed curves were used to derive a correlation of the drop size with the capillary number (Ca) that was used to calculate the DIT at low surfactant concentrations and short times down to $3 \mathrm{~ms}$, due to the extended ranges of capillary number $(0.024 \leq \mathrm{Ca} \leq 0.263)$. The results were discussed in terms of the surfactant adsorption and diffusion time scales.

Previous experimental DIT studies discussed the results on the basis of surfactant mass transfer (diffusive or convective) only $[6,18,19,30]$. In this work we show that adsorption times are comparable to drop formation times for the TX100 surfactant at all 
studied concentrations and thus the kinetic adsorption step at the interface should not be neglected. For SDS and DTAB surfactants it was found that the adsorption time is longer than the diffusion time for concentrations above CMC, but it does not exceed the drop formation time. Thus, equilibrium interfacial tension can be reached at high concentrations. DIT was, however, observed at low concentrations below CMC which has not been reported by similar systems in the literature $[18,19,21]$. As a result, the drop formation time for equilibrium interfacial tension in a microfluidic device depends on surfactant type according to $t / t_{s}>1$ for TX100, $t / t_{s}>110$ for DTAB and $t / t_{s}>240$ for SDS, where $t_{s}$ is the characteristic time scale for the surfactant mass transport. The proposed normalised drop formation times will ensure that equilibrium interfacial tension has been reached and DIT effects will not influence the drop size. The methodology can be used to develop selection criteria for other surfactants and operating conditions.

In future work we will investigate the velocity fields and possible circulation patterns inside the drops and in the continuous phase with particle image velocimetry to understand the effects of convection on the surfactant mass transport.

\section{CRediT authorship contribution statement}

Maria Kalli: Conceptualization, Investigation, Methodology, Project administration, Data curation, Visualization, Writing - original draft, Software, Formal analysis. Loïc Chagot: Writing - review \& editing, Validation. Panagiota Angeli: Supervision, Writing review \& editing, Resources, Conceptualization, Funding acquisition.

\section{Declaration of Competing Interest}

The authors declare that they have no known competing financial interests or personal relationships that could have appeared to influence the work reported in this paper.

\section{Acknowledgments}

The authors would like to acknowledge support from the UK Engineering and Physical Sciences Research Council (EPSRC) Programme Grant PREMIERE (EP/T000414/1). M Kalli would also like to acknowledge the EPSRC Doctoral Training Programme (EP/ R513143/1) for her studentship.

\section{Appendix A. Supplementary material}

Supplementary data to this article can be found online at https://doi.org/10.1016/j.jcis.2021.06.178.

\section{References}

[1] A.L. Dessimoz, L. Cavin, A. Renken, L. Kiwi-Minsker, Liquid-liquid two-phase flow patterns and mass transfer characteristics in rectangular glass microreactors, Chem. Eng. Sci. 63 (2008) 4035-4044, https://doi.org/10.1016/ j.ces.2008.05.005

[2] T. Cubaud, T.G. Mason, Capillary threads and viscous droplets in square microchannels, Phys. Fluids. 20 (2008), https://doi.org/10.1063/1.2911716.

[3] S. Van Der Graaf, C.G.P.H. Schroën, R.G.M. Van Der Sman, R.M. Boom, Influence of dynamic interfacial tension on droplet formation during membrane emulsification, J. Colloid Interface Sci. 277 (2004) 456-463, https://doi.org/ 10.1016/j.jcis.2004.04.033.

[4] J.G. Kralj, H.R. Sahoo, K.F. Jensen, Integrated continuous microfluidic liquidliquid extraction, Lab Chip. 7 (2007) 256-263, https://doi.org/10.1039/ b610888a.

[5] M.J. Lawrence, G.D. Rees, Microemulsion-based media as novel drug delivery systems, Adv. Drug Deliv. Rev. 64 (2012) 175-193, https://doi.org/10.1016/j. addr.2012.09.018.
[6] M. Moiré, Y. Peysson, B. Herzhaft, N. Pannacci, F. Gallaire, L. Augello, C. Dalmazzone, A. Colin, Ultralow Interfacial Tension Measurement through Jetting/Dripping Transition, Langmuir. 33 (2017) 2531-2540, https://doi.org/ 10.1021/acs.langmuir.7b00076.

[7] L. Yang, N. Kapur, Y. Wang, F. Fiesser, F. Bierbrauer, M.C.T. Wilson, T. Sabey, C.D. Bain, Drop-on-demand satellite-free drop formation for precision fluid delivery, Chem. Eng. Sci. 186 (2018) 102-115, https://doi.org/10.1016/j. ces.2018.04.014.

[8] S. Santra, S. Das, S.S. Das, S. Chakraborty, Surfactant-induced retardation in lateral migration of droplets in a microfluidic confinement, Microfluid. Nanofluidics. 22 (2018) 1-19, https://doi.org/10.1007/s10404-018-2109-6.

[9] N. Mucic, A. Javadi, N.M. Kovalchuk, E.V. Aksenenko, R. Miller, Dynamics of interfacial layers-Experimental feasibilities of adsorption kinetics and dilational rheology, Adv. Colloid Interface Sci. 168 (2011) 167-178, https:// doi.org/10.1016/j.cis.2011.06.001.

[10] A. Javadi, N. Mucic, M. Karbaschi, J.Y. Won, M. Lotfi, A. Dan, V. Ulaganathan, G. Gochev, A.V. Makievski, V.I. Kovalchuk, N.M. Kovalchuk, J. Krägel, R. Miller, Characterization methods for liquid interfacial layers, Eur. Phys. J. Spec. Top. 222 (2013) 7-29, https://doi.org/10.1140/epjst/e2013-01822-3.

[11] A. Passerone, L. Liggieri, N. Rando, F. Ravera, E. Ricci, A new experimental method for the measurement of the interfacial tension between immiscible fluids at zero bond number, J. Colloid Interface Sci. 146 (1991) 152-162, https://doi.org/10.1016/0021-9797(91)90012-W.

[12] U. Teipel, N. Aksel, Adsorption behavior of nonionic surfactants studied by drop volume technique, Chem. Eng. Technol. 24 (2001) 393-400, https://doi org/10.1002/1521-4125(200104)24:4<393::AID-CEAT393>3.0.CO;2-T.

[13] A. Javadi, J. Krägel, A.V. Makievski, V.I. Kovalchuk, N.M. Kovalchuk, N. Mucic, G. Loglio, P. Pandolfini, M. Karbaschi, R. Miller, Fast dynamic interfacial tension measurements and dilational rheology of interfacial layers by using the capillary pressure technique, Colloids Surfaces A Physicochem. Eng. Asp. 407 (2012) 159-168, https://doi.org/10.1016/j.colsurfa.2012.05.026.

[14] N.M. Kovalchuk, E. Roumpea, E. Nowak, M. Chinaud, P. Angeli, M.J.H. Simmons, Effect of surfactant on emulsification in microchannels, Chem. Eng. Sci. 176 (2018) 139-152, https://doi.org/10.1016/j.ces.2017.10.026.

[15] C.A. MacLeod, C.J. Radke, Surfactant exchange kinetics at the air/water interface from the dynamic tension of growing liquid drops, J. Colloid Interface Sci. 166 (1994) 73-88, https://doi.org/10.1006/jcis.1994.1273.

[16] Y. He, P. Yazhgur, A. Salonen, D. Langevin, Adsorption-desorption kinetics of surfactants at liquid surfaces, Adv. Colloid Interface Sci. 222 (2015) 377-384, https://doi.org/10.1016/j.cis.2014.09.002.

[17] Q. Brosseau, J. Vrignon, J.C. Baret, Microfluidic Dynamic Interfacial Tensiometry ( $\mu$ DIT), Soft Matter. 10 (2014) 3066-3076, https://doi.org/ $10.1039 / \mathrm{c} 3 \mathrm{sm} 52543 \mathrm{k}$.

[18] K. Wang, Y.C. Lu, J.H. Xu, G.S. Luo, Determination of dynamic interfacial tension and its effect on droplet formation in the T-shaped microdispersion process, Langmuir. 25 (2009) 2153-2158, https://doi.org/10.1021/la803049s.

[19] K. Wang, L. Zhang, W. Zhang, G. Luo, Mass-Transfer-Controlled Dynamic Interfacial Tension in Microfluidic Emulsification Processes, Langmuir. 32 (2016) 3174-3185, https://doi.org/10.1021/acs.langmuir.6b00271.

[20] J.H. Xu, G.S. Luo, S.W. Li, G.G. Chen, Shear force induced monodisperse droplet formation in a microfluidic device by controlling wetting properties, Lab Chip. 6 (2006) 131-136, https://doi.org/10.1039/b509939k.

[21] J.H. Xu, P.F. Dong, H. Zhao, C.P. Tostado, G.S. Luo, The dynamic effects of surfactants on droplet formation in coaxial microfluidic devices, Langmuir. 28 (2012) 9250-9258, https://doi.org/10.1021/la301363d.

[22] E. Roumpea, N.M. Kovalchuk, M. Chinaud, E. Nowak, M.J.H. Simmons, P. Angeli, Experimental studies on droplet formation in a flow-focusing microchannel in the presence of surfactants, Chem. Eng. Sci. 195 (2019) 507-518, https://doi. org/10.1016/j.ces.2018.09.049.

[23] J.D. Martin, S.D. Hudson, Mass transfer and interfacial properties in two-phase microchannel flows, New J. Phys. 11 (2009), https://doi.org/10.1088/13672630/11/11/115005.

[24] L.W. Honaker, J.P.F. Lagerwall, V.S.R. Jampani, Microfluidic Tensiometry Technique for the Characterization of the Interfacial Tension between Immiscible Liquids, Langmuir. 34 (2018) 2403-2409, https://doi.org/ 10.1021/acs.langmuir.7b03494.

[25] C.P. Tostado, J.H. Xu, A.W. Du, G.S. Luo, Experimental study on dynamic interfacial tension with mixture of SDS-PEG as surfactants in a coflowing microfluidic device, Langmuir. 28 (2012) 3120-3128, https://doi.org/10.1021/ la204852w.

[26] J. Tan, J.H. Xu, S.W. Li, G.S. Luo, Drop dispenser in a cross-junction microfluidic device: Scaling and mechanism of break-up, Chem. Eng. J. 136 (2008) 306-311, https://doi.org/10.1016/j.cej.2007.04.011.

[27] S.L. Anna, N. Bontoux, H.A. Stone, Formation of dispersions using "flow focusing" in microchannels, Appl. Phys. Lett. 82 (2003) 364-366, https://doi. org/10.1063/1.1537519.

[28] P. Garstecki, H.A. Stone, G.M. Whitesides, Mechanism for flow-rate controlled breakup in confined geometries: A route to monodisperse emulsions, Phys. Rev. Lett. 94 (2005) 1-4, https://doi.org/10.1103/PhysRevLett.94.164501.

[29] J.H. Xu, S.W. Li, W.J. Lan, G.S. Luo, Microfluidic Approach for Rapid Interfacial Tension Measurement, Langmuir. 24 (2008) 11287-11292, https://doi.org/ 10.1021/la801526n.

[30] K. Muijlwijk, E. Hinderink, D. Ershov, C. Berton-Carabin, K. Schroën, Interfacial tension measured at high expansion rates and within milliseconds using microfluidics, J. Colloid Interface Sci. 470 (2016) 71-79, https://doi.org/ 10.1016/j.jcis.2016.02.041. 
[31] A. Riaud, H. Zhang, X. Wang, K. Wang, G. Luo, Numerical Study of Surfactant Dynamics during Emulsification in a T-Junction Microchannel, Langmuir. 34 (2018) 4980-4990, https://doi.org/10.1021/acs.langmuir.8b00123.

[32] S. Van Der Graaf, T. Nisisako, C.G.P.H. Schroën, R.G.M. Van Der Sman, R.M. Boom, Lattice Boltzmann simulations of droplet formation in a T-shaped microchannel, Langmuir. 22 (2006) 4144-4152, https://doi.org/10.1021/ la052682f.

[33] F. Jin, N.R. Gupta, K.J. Stebe, The detachment of a viscous drop in a viscous solution in the presence of a soluble surfactant, Phys. Fluids. 18 (2006), https:// doi.org/10.1063/1.2172003.

[34] A. Javadi, N. Mucic, D. Vollhardt, V.B. Fainerman, R. Miller, Effects of dodecanol on the adsorption kinetics of SDS at the water-hexane interface, J. Colloid Interface Sci. 351 (2010) 537-541, https://doi.org/10.1016/j.jcis.2010.07.033.

[35] J. Cosby, P. Starck, D. Littlewood, O.O. Mykhaylyk, A.J. Ryan, Co-assembly and Structure of Sodium Dodecylsulfate and other n-Alkyl Sulfates in Glycerol: nAlkyl Sulfate-Glycerol Crystal Phase, J. Colloid Interface Sci. 596 (2021) 442454, https://doi.org/10.1016/j.jcis.2021.03.063.

[36] L. Matthews, Ż. Przybyłowicz, S.E. Rogers, P. Bartlett, A.J. Johnson, R. Sochon, W.H. Briscoe, The curious case of SDS self-assembly in glycerol: Formation of a lamellar gel, J. Colloid Interface Sci. 572 (2020) 384-395, https://doi.org/ 10.1016/j.jcis.2020.03.102.

[37] N.M. Kovalchuk, M. Sagisaka, K. Steponavicius, D. Vigolo, M.J.H. Simmons, Drop formation in microfluidic cross-junction: jetting to dripping to jetting transition, Microfluid. Nanofluidics. 23 (2019), https://doi.org/10.1007/ s10404-019-2269-z.

[38] I.W. Hamley, Introduction to Soft Matter: Synthetic and Biological SelfAssembling Materials (2007), https://doi.org/10.1002/9780470517338.

[39] J.K. Ferri, K.J. Stebe, Which surfactants reduce surface tension faster? A scaling argument for diffusion-controlled adsorption, Adv. Colloid Interface Sci. 85 (2000) 61-97, https://doi.org/10.1016/S0001-8686(99)00027-5.

[40] Y. Chen, J.H. Xu, G.S. Luo, The dynamic adsorption of different surfactants on droplet formation in coaxial microfluidic devices, Chem. Eng. Sci. 138 (2015) 655-662, https://doi.org/10.1016/j.ces.2015.08.048.

[41] V.L. Wong, K. Loizou, P.L. Lau, R.S. Graham, B.N. Hewakandamby, Numerical studies of shear-thinning droplet formation in a microfluidic T-junction using two-phase level-SET method, Chem. Eng. Sci. 174 (2017) 157-173, https://doi. org/10.1016/j.ces.2017.08.027.

[42] T. Fu, Y. Ma, H.Z. Li, Breakup dynamics of slender droplet formation in shearthinning fluids in flow-focusing devices, Chem. Eng. Sci. 144 (2016) 75-86, https://doi.org/10.1016/j.ces.2015.12.031.

[43] S. Van Der Graaf, M.L.J. Steegmans, R.G.M. Van Der Sman, C.G.P.H. Schroën, R. M. Boom, Droplet formation in a T-shaped microchannel junction: A model system for membrane emulsification, Colloids Surfaces A Physicochem. Eng. Asp. 266 (2005) 106-116, https://doi.org/10.1016/j.colsurfa.2005.06.019.

[44] M. Liu, Y. Zheng, Y. Liu, Z. Zhang, Y. Wang, Q. Chen, J. Li, J. Li, Y. Huang, Q. Yin, Effects of surfactant adsorption on the formation of compound droplets in microfluidic devices, RSC Adv. 9 (2019) 41943-41954, https://doi.org/10.1039/ c9ra07141e.

[45] J.M. Montanero, A.M. Gañán-Calvo, Dripping, jetting and tip streaming, Reports Prog. Phys. 83 (2020), https://doi.org/10.1088/1361-6633/aba482.

[46] J.H. Xu, S.W. Li, J. Tan, G.S. Luo, Correlations of droplet formation in T-junction microfluidic devices: From squeezing to dripping, Microfluid. Nanofluidics. 5 (2008) 711-717, https://doi.org/10.1007/s10404-008-0306-4.

[47] J.C. Baret, O.J. Miller, V. Taly, M. Ryckelynck, A. El-Harrak, L. Frenz, C. Rick, M.L. Samuels, J.B. Hutchison, J.J. Agresti, D.R. Link, D.A. Weitz, A.D. Griffiths, Fluorescence-activated droplet sorting (FADS): Efficient microfluidic cell sorting based on enzymatic activity, Lab Chip. 9 (2009) 1850-1858, https:// doi.org/10.1039/b902504a.

[48] M.A. Partearroyo, S.J. Pilling, M.N. Jones, The effects of surfactants on the permeability of isolated perfused fish gills to urea, Comp. Biochem. Physiol. Part A Physiol. 101 (1992) 653-659, https://doi.org/10.1016/0300-9629(92) 90339-R.

[49] S.N. Moorkanikkara, D. Blankschtein, New methodology to determine the ratelimiting adsorption kinetics mechanism from experimental dynamic surface tension data, J. Colloid Interface Sci. 302 (2006) 1-19, https://doi.org/10.1016/ j.jcis.2006.06.022.

[50] A.F.H. Ward, L. Tordai, Time-dependence of boundary tensions of solutions I. The role of diffusion in time-effects, J. Chem. Phys. 14 (1946) 453-461, https:// doi.org/10.1063/1.1724167.

[51] J. Van Hunsel, P. Joos, Adsorption kinetics at the oil/water interface, Colloids and Surfaces. 24 (1987) 139-158, https://doi.org/10.1016/0166-6622(87) 80346-3.

[52] J. Eastoe, J.S. Dalton, Dynamic surface tension and adsorption mechanisms of surfactants at the air-water interface, Adv. Colloid Interface Sci. 85 (2000) 103-144, https://doi.org/10.1016/S0001-8686(99)00017-2.

[53] N.J. Alvarez, L.M. Walker, S.L. Anna, Diffusion-limited adsorption to a spherical geometry: The impact of curvature and competitive time scales, Phys. Rev. E Stat. Nonlinear, Soft Matter Phys. 82 (2010) 1-8, https://doi.org/10.1103/ PhysRevE.82.011604.

[54] V.B. Fainerman, D. Möbius, R. Miller, Surfactants-chemistry, interfacial properties and application, Elsevier, 2001, https://doi.org/10.1016/S13837303(01)80061-2.

[55] T. Glawdel, C.L. Ren, Droplet formation in microfluidic T-junction generators operating in the transitional regime. III. Dynamic surfactant effects, Phys. Rev. E - Stat. Nonlinear, Soft Matter Phys. 86 (2012) 1-12, https://doi.org/10.1103/ PhysRevE.86.026308.

[56] F. Jin, R. Balasubramaniam, K.J. Stebe, Surfactant adsorption to spherical particles: The intrinsic length scale governing the shift from diffusion to kinetic-controlled mass transfer, J. Adhes. 80 (2004) 773-796, https://doi.org/ 10.1080/00218460490480770.

[57] N.J. Alvarez, D.R. Vogus, L.M. Walker, S.L. Anna, Using bulk convection in a microtensiometer to approach kinetic-limited surfactant dynamics at fluidfluid interfaces, J. Colloid Interface Sci. 372 (2012) 183-191, https://doi.org/ 10.1016/j.jcis.2011.12.034.

[58] K. Muijlwijk, W. Huang, J.E. Vuist, C. Berton-Carabin, K. Schroën, Convective mass transport dominates surfactant adsorption in a microfluidic Y-junction, Soft Matter. 12 (2016) 9025-9029, https://doi.org/10.1039/c6sm01677d.

[59] C.R. Wilke, P. Chang, Correlation of diffusion coefficients in dilute solutions, AIChE J. 1 (1955) 264-270, https://doi.org/10.1002/aic.690010222.

[60] K.P. Das, A. Ceglie, B. Lindman, S.E. Friberg, Fourier transform NMR selfdiffusion studies of a nonaqueous microemulsion system, J. Colloid Interface Sci. 116 (1987) 390-400, https://doi.org/10.1016/0021-9797(87)90135-4.

[61] B. Li, G. Geeraerts, P. Joos, Kinetic equations for transfer-controlled adsorption kinetics, Colloids Surfaces A Physicochem. Eng. Asp. 88 (1994) 251-266, https://doi.org/10.1016/0927-7757(94)02791-9.

[62] P.M. Gassin, G. Martin-Gassin, D. Meyer, J.F. Dufrêche, O. Diat, Kinetics of Triton-X100 transfer across the water/dodecane interface: Analysis of the interfacial tension variation, J. Phys. Chem. C. 116 (2012) 13152-13160, https://doi.org/10.1021/jp302514k.

[63] R. Sharma, Small-Molecule Surfactant Adsorption, Polymer Surfactant Adsorption, and Surface Solubilization, An Overview (1996) 1-20, https:// doi.org/10.1021/bk-1995-0615.ch001. 